\title{
CRYSTALLOGRAPHIC RELATIONSHIPS BETWEEN DIAMOND AND ITS OLIVINE INCLUSIONS
}

\author{
Nestola $\mathbf{F}^{1}$, Nimis $* \mathbf{P}^{1}$ and Harris $\mathbf{J W}^{\mathbf{2}}$ \\ ${ }^{1}$ Dipartimento di Geoscienze, Università di Padova, Italy \\ ${ }^{2}$ School of Geographical and Earth Sciences, University of Glasgow, UK
}

\section{INTRODUCTION}

Much of what we have learned over the last fifty years about diamond genesis and distribution in the Earth's mantle has been obtained through the study of its mineral inclusions. These represent unique samples of the Earth's mantle which have been encapsulated during diamond formation. Their mineralogy, geochemistry and isotopic composition can be used to gain an insight into the physicochemical environment and timing of diamond forming processes (e.g., Richardson and Harris, 1997; Pearson and Shirey, 1999; Stachel et al., 2004).

Models of diamond genesis in space and time often rely on the assumption that most inclusions are syngenetic, i.e., they have formed or re-crystallized completely along with the host diamond. If this is the case, any geological information extracted from the inclusions should also apply to their host diamond. Data obtained from the inclusions would thus place unequivocal constraints on the nature and age of the geochemical medium that generated the diamond. If the inclusions are instead protogenetic, i.e., they have formed before the diamond, they might record conditions that existed long before their encapsulation and were thus totally unrelated to diamond formation. Indeed, should most inclusions be demonstrably protogenetic, this would support models of diamond formation involving fluxes of C-bearing fluids through preexisting mantle rocks (e.g., Thomassot et al., 2009). Moreover, several geochronological data for diamonds would probably have to be reconsidered.

Discrimination of syngenicity and protogenicity, however, is not straightforward. This difficulty has prompted a strong debate in the last few years on the real significance of many assumed "syngenetic" inclusions (cf. Taylor et al., 2003). The most commonly used "proof" of syngenesis is the imposition of the morphology of the diamond on the inclusion (e.g., Harris, 1968, 1979; Sobolev, 1974; Sobolev et al., 1969, 1972; Harris and Gurney, 1979; Meyer 1985, 1987; Pearson and Shirey, 1999). The recognition of several harzburgitic garnets with diamond-imposed morphology having trace element compositions indicative of multi-stage geochemical evolution and, therefore, protogenesis (Taylor et al., 2003) has challenged this widely used criterion. It has been suggested that an epitactic relation between an inclusion and its host would represent a more robust proof of syngenicity (Harris, 1969, 1979; Pearson and Shirey, 1999). Yet the crystallographic relations between inclusions and their hosts are rarely determined and a systematic survey of these relations for the different mineral species is lacking or has been restricted to limited sets of samples.

Most of the available data on olivine inclusions date back to the fifties and sixties. Mitchell and Giardini (1953) noted that the (101) and (010) planes of two olivines in two diamonds were aligned approximately parallel to the (101) and, respectively, (111) faces of the diamond. Futergendler and Kamenetsky (1961) and Kamenetsky (1964) found the same orientation in some of their olivines, but also other two types of relationships: (010)oli // (311)dia and (101)oli // (130)dia; (010)oli // (320)dia. Harris (1968) studied thirteen olivines and found that, although some orientations were apparently recurrent, some degree of random angular mis-orientations existed from one sample to another. More recently, Satitkune et al. (2010) reported that “...olivine inclusions showed a degree of mis-orientation...up to $12.9^{\circ}$ between diamond [111] and olivine [100]."

Modern in-situ single-crystal X-ray analysis can provide a relatively quick, high-quality, non-destructive, threedimensional examination of the geometrical relations between the crystal lattices of the inclusion and of the diamond host. As part of a new systematic investigation of crystallographic relationships between diamond and its inclusions, in order to provide new information on their singenetic vs. protogenetic nature, we have investigated 11 olivines which exhibit imposed cubo-octahedral habits in 6 diamonds from Udachnaya (Yakutia).

\section{EXPERIMENTAL}

The orientations of the crystal lattices of olivine and diamond were determined using a single-crystal X-ray diffractometer equipped with a CCD areal detector. The angles between crystallographic planes of the olivine and diamond were measured from the crystallographic 


\section{$10^{\text {th }}$ International Kimberlite Conference, Bangalore - 2012}

orientation matrixes obtained for the two minerals. We have considered all crystallographic planes of olivine with reasonably low $h k l$ index values (typically $\leq 3$ ), lying within $15^{\circ}$ of cubo-octahedral forms $\{111\}$ and $\{100\}$ or of other low-index rational planes of the host diamond.

Some of the diamonds contained multiple olivine inclusions. In this case specific measurements were carried out on each of the inclusions, provided they were of sufficient size (> ca. $100 \mu \mathrm{m}$ ) to ensure their accurate centering under the X-ray beam and acquisition of goodquality diffraction data. In one of the six diamonds two olivine inclusions were studied. In two other diamonds three inclusions were studied. In the remaining three diamonds only one inclusion was studied.

\section{RESULTS}

The measured orientations of the olivines relative to the host diamond are listed in Table 1. Our data indicate that it is almost always possible to find olivine crystallographic planes with reasonably low $h k l$ values lying within $<10^{\circ}$ of the octahedral [111] faces of the diamond. Nonetheless, the reciprocal orientations do not appear to be systematic, and may change significantly from one inclusion to another. The real significance of these olivine planes in terms of epitaxy thus remains questionable. In particular, no olivine among those studied by us shows an orientation comparable to that found by Mitchell and Giardini (1953) for olivines with similar cubo-octahedral imposed morphology, or to those reported by Satitkune et al. (2010). Other orientations, such as those found by Futergendler and Frank-Kamenetsky (1961) and Frank-Kamenetsky (1964), which involved parallelism with non-cubo-octahedral faces of the diamond (311), (130), (320), are not relevant in our cases.

Absence of a systematic crystallographic relationship has two possible alternative explanations: (i) most, if not all, inclusions among those studied here are protogenetic, and were passively incorporated into the diamond maintaining random orientations; this hypothesis implies that the form energy of the diamond, in some way, is great enough to modify the original shape of the inclusion during or after its entrainment; (ii) the inclusions are syngenetic, but the reduction of the interfacial energy at olivine-diamond interfaces is too small to favour a particular orientation during simultaneous growth of the olivine and diamond. If the second hypothesis is correct, we may predict that an epitaxial growth of syngenetic inclusions would or would not occur depending on small variations of environmental factors which may have a significant influence on growth kinetics and processes (e.g., the degree of supersaturation). One of the most intriguing results is perhaps that in our sample set the only two olivines with identical orientation [i.e., (111)dia // (123)oli with (011)dia // (201)oli] are from a single diamond. A third olivine from the same diamond instead shows a completely different relationship. In the absence of an unequivocal indication for syngenesis or protogenesis, this finding has two possible interpretations. If the inclusions with identical orientation were protogenetic, they might be portions of the same original monocrystal, which was split into two distinct inclusions by a mechanism similar to "necking", a common aging process that occurs during maturation of fluid inclusions. If the inclusions with identical orientation were syngenetic, then they have probably grown under identical environmental conditions, i.e., they were probably contemporaneous.

Table 1. Crystallographic relationships between olivine inclusions and diamonds.

\begin{tabular}{|c|c|c|}
\hline Diamond & Inclusion & Angles between planes \\
\hline 1 & a & $\begin{array}{l}\text { (111)dia // } 10.9^{\circ} / /(010) \text { oli } \\
\text { (111)dia // } 0.3^{\circ} / /(133) \text { oli }\end{array}$ \\
\hline 2 & a & $\begin{array}{l}\text { (111)dia // } 6.7^{\circ} / /(010) \text { oli } \\
\text { (101)dia // } 24.1^{\circ} / /(101) \text { oli } \\
\text { (111)dia // 0.0 // (331)oli }\end{array}$ \\
\hline \multirow{3}{*}{3} & $\mathrm{a}$ & $\begin{array}{l}\text { (111)dia // } 4.5^{\circ} / /(132) \text { oli } \\
\text { (001)dia // } 8.4^{\circ} / /(010) \text { oli }\end{array}$ \\
\hline & $\mathrm{b}$ & $\begin{array}{l}\text { (111)dia // } 0.7^{\circ} / /(121) \text { oli } \\
\text { (001)dia // } 0.3^{\circ} / /(010) \text { oli }\end{array}$ \\
\hline & $\mathrm{c}$ & $\begin{array}{l}\text { (111)dia // 1.2 // (131)oli } \\
\text { (001)dia // 12.2 // (010)oli }\end{array}$ \\
\hline \multirow{3}{*}{4} & $\mathrm{a}$ & $\begin{array}{l}\text { (111)dia // } 1.0^{\circ} / /(123) \text { oli } \\
\text { (011)dia // } 0.4^{\circ} / /(201) \text { oli }\end{array}$ \\
\hline & $\mathrm{b}$ & $\begin{array}{l}\text { (111)dia // } 1.0^{\circ} / /(123) \text { oli } \\
\text { (011)dia // } 0.0^{\circ} / /(201) \text { oli }\end{array}$ \\
\hline & $\mathrm{c}$ & $\begin{array}{l}\text { (111)dia // } 2.0^{\circ} / /(353) \text { oli } \\
\text { (011)dia // } 12.3^{\circ} / /(201) \text { oli }\end{array}$ \\
\hline 5 & a & $\begin{array}{l}\text { (111)dia // } 0.8^{\circ} / /(010) \mathrm{oli} \\
\text { (001)dia // } 2.5^{\circ} / /(132) \mathrm{oli}\end{array}$ \\
\hline \multirow{2}{*}{6} & $\mathrm{a}$ & $\begin{array}{l}\text { (111)dia // } 2.0^{\circ} / /(001) \text { oli } \\
\text { (001)dia // 6.8 // (101)oli }\end{array}$ \\
\hline & $\mathrm{b}$ & $\begin{array}{l}\text { (100)dia // 5.2 // (131)oli } \\
\text { (001)dia // 8.1 } / /(103) \text { oli }\end{array}$ \\
\hline
\end{tabular}

\section{CONCLUSIONS}

Our preliminary data on eleven inclusions in six diamonds indicate a wide range of possible orientations for olivine in diamond. The significance of this result in terms of syngenesis vs. protogenesis cannot be determined at this stage and requires quantitative evaluation of interfacial energies between olivine and diamond in a number of possible reciprocal orientations.

Such evaluation is not straightforward and can only be made through ab-initio quantum-mechanical calculations. These calculations will show whether the observed orientation relationships are energetically favoured or not. Should a specific orientation turn out to be the most favoured for diamond-olivine pairs, then most, if not all, the inclusions studied here will have to be classified as protogenetic. Should the calculated interface energies 


\section{$10^{\text {th }}$ International Kimberlite Conference, Bangalore - 2012}

among the different faces be practically equal, then the question of syngenesis vs. protogenesis will be impossible to answer on the basis of crystallographic relationships.

Our database is being extended to improve the statistical significance of our results for both single and multiple inclusions of olivine and for other major mineral inclusions in diamonds.

\section{REFERENCES}

Frank-Kamenetsky, V.A. (1964) The nature of structural impurities and inclusions in diamond. Publications of Leningrad State University, Section 9, pp. 161-169 (in Russian).

Futergendler, S.I., Frank-Kamenetsky, V.A. (1961) Oriented inclusions of olivine, garnet and chrome-spinel in diamonds. Zapisky Vsesoyuznogo Mineralogicheskogo Obshestva, 90, 230-236 (in Russian).

Harris, J.W. (1968) The recognition of diamond inclusions. Pt. 1: Syngenetic inclusions. Industrial Diamond Rev., 28, 402-410.

Harris, J.W. (1979) Inclusions in diamond. In The Properties of Diamond, Ed. J.E. Field, Academic Press, London, 555-591.

Harris, J.W., Gurney, J.J. (1979) Inclusions in diamonds. In Properties of Diamond (ed. J.E. Field), Academic Press, London, 555-591.

Meyer, H.O.A. (1985) Genesis of diamond: A mantle saga. Amer. Mineral. $70,344-355$.

Meyer, H.O.A. (1987) Inclusions in diamonds: In Nixon, P. H. (Ed.), Mantle Xenoliths, Wiley, Chichester, pp. 501-523.

Mitchell, R.S., Giardini, A.A. (1953) Oriented olivine inclusions in diamond. Am. Mineral., 38, 136-138.

Pearson, D.G., Shirey, S.B. (1999) Isotopic dating of diamonds. Econ. Geol. Spec. Publ., SEG Reviews, Ch. 6, 143-171.

Richardson, S.H., Harris, J.W. (1997) Antiquity of peridotitic diamonds from the Siberian craton. Earth Planet. Sci. Lett., 151, 271-277.

Satitkune, S., Zubko, M., Häger, T., Kusz, J., Hofmeister, W. (2010) Mineral chemistry and structural relationships of inclusions in diamond crystals. IMA Congress Abstract Volume, Budapest.

Sobolev, N.V. (1974) Deep-Seated Inclusions in Kimberlites and the Problem of the Composition of the Upper Mantle. Nauka, Novosibirsk, 264 p. (in Russian; English version published in 1977, Publ. Amer. Geophys. Union, Wash., DC, 279 p.)

Sobolev, N.V., Lavrent'ev, Y.G., Pospelova, L.N., Sobolev, E.V. (1969) Chrome pyropes from the diamonds of Yakutia. Dokl. Akad. Nauk SSSR, 189, 162-165.

Sobolev, V.S., Sobolev, N.V., Lavrent'ev, Y.G. (1972) Inclusions in diamonds from a diamond-bearing eclogite: Dokl. Akad. Nauk. SSR, v. 207 , p. 164-167.

Stachel, T., Aulbach, S., Brey, G.P., Harris, J.W., Leost, I., Tappert, R., Viljoen, K.S. (2004) The trace element composition of silicate inclusions in diamonds: a review. Lithos, 77, 1-19.

Taylor, L.A., Anand, M., Promprated, P., Floss, C., Sobolev, N.V. (2003) The significance of mineral inclusions in large diamonds from Yakutia, Russia. Am. Mineral., 88, 912-920.

Thomassot, E., Cartigny, P., Harris, J.W., Lorand, J.P., Rollion-Bard, C. and Chaussidon, M. (2009) Metasomatic diamond growth: A multiisotope study $\left({ }^{13} \mathrm{C},{ }^{15} \mathrm{~N},{ }^{33} \mathrm{~S},{ }^{34} \mathrm{~S}\right)$ of sulphide inclusions and their host diamonds from Jwaneng (Botswana). Earth Planet. Sci. Lett., 282, 7990 . 